\title{
PEMANFAATAN TEGAKAN Acacia auriculiformis SEBAGAI POHON PENAUNG DAN INANG TANAMAN CENDANA (Santalum Album Linn)
}

\author{
The Use of Acacia auriculiformis Stand as Shading Trees and Host Plant of Sandalwood \\ I Komang Surata \\ Balai Penelitian Kehutanan Kupang \\ J1. Untung Suropati No. 7 Po. Box. 67 Kupang 85115 \\ Telp. (0380) 823357 Fax. (0380)831068 \\ Email : irat_2006@yahoo.com Hp.08124604124
}

Naskah masuk : 12 Desember 2009; Naskah diterima : 15 November 2010

\begin{abstract}
Acacia (Acacia auriculiformis) stand is one of alternatives that can be used as shading trees and host plant of sandalwood. The utilization of acacia as shading trees and host plant that is too dense and long periode will decrease the growth of sandalwood plant because competition will arise. Therefore, canopy dense is need to reduce which one of the alternatives the use of pruning method. The objective of this research was to observe the effects of reducing canopy covering of acacia as shading trees and host plant with pruning method on sandalwood plant growth. Sandalwood was planted under 5 years old. Acacia tree resulted from reforestration with stand density $6 \times 6 \mathrm{~m}$ and with the canopy that began to close. The eksperiment was conducted in Randomized Block Design method with the treatment is pruning intensity of acacia stand earleaf i.e. $0 \%, 25 \%, 50 \%, 75 \%, 100 \%$ per tree that was done on 2 years old and continuing every years until 8 years old. Experiment was done in 3 blocks and each blocks consisted of 25 replications. The result of this experiment proved that the pruning on 8 years old of shading tree or host plant had significant effects to increase the height, diameter, and survival percentage of sandalwood plant namely $44 \%, 40 \%$, and $104 \%$ respectively. The maximum survival percentages of sandalwood at 5 years old was done $75 \%$ and 8 years old $91 \%$. The pruning could increase $14 \%$ of air temperature and $53 \%$ of light radiation. The light intensity was significant to increase survival percentages of sandalwood plants.
\end{abstract}

Keywords: Shading trees, host plant, sandalwood, branch pruning, Acacia auriculiformis stand

\begin{abstract}
ABSTRAK
Tegakan acasia (Acacia auriculiformis) adalah salah satu alternatif yang dapat dimanfaatkan sebagai pohon penaung dan inang cendana. Penggunaan acasia sebagai pohon penaung atau inang yang terlalu rapat dan dalam waktu yang lama akan menurunkan pertumbuhan tanaman cendana karena persaingan akan semakin meningkat, oleh sebab itu pada kerapatan penaung dan umur tertentu perlu dilakukan pengurangan penutupan tajuk salah satunya dengan cara pemangkasan cabang. Tujuan penelitian ini adalah untuk mengetahui pengaruh pengurangan penutupan tajuk A. auriciliformis sebagai pohon penaung dan inang dengan cara pemangkasan cabang terhadap pertumbuhan tanaman cendana. Penanaman cendana dilakukan di bawah tegakan A. auriculiformis hasil dari tanaman reboisasi yang telah berumur 5 tahun dengan kerapatan tegakan $6 \times 6 \mathrm{~m}$ dan tajuknya mulai menutup. Penelitian disusun dalam Rancangan Acak Berblok dengan perlakuan pemangksan cabang tegakan A. auriculiformis : $0 \%, 25 \%, 50 \%, 75 \%, 100 \%$ per pohon yang dilakukan pada umur 2 tahun setelah tanam dan selanjutnya setiap tahun dilakukan pemangkasan terubusan cabang sampai umur 8 tahun. Perlakuan terdiri dari 3 blok dan setiap blok terdiri dari 25 ulangan. Hasil penelitian menunjukkan bahwa pada umur 8 tahun pemangkasan cabang pohon penaung atau inang nyata meningkatkan tinggi, diameter, dan persen hidup tanaman cendana masing-masing $45 \%$, $48 \%$, dan $107 \%$. Persen hidup tanaman cendana paling baik dihasilkan pada perlakuan pemangkasan cabang umur 3 tahun sebanyak $76 \%$ dan umur 8 tahun $91 \%$. Pemangkasan cabang dapat meningkatkan temperatur udara $14 \%$ dan intensitas cahaya matahari $53 \%$. Intensitas cahaya matahari nyata meningkatkan persen hidup tanaman cendana.
\end{abstract}

Kata kunci: Pohon penaung, tanaman inang, cendana, pemangksan cabang, tegakan Acacia auriculiformis 


\section{PENDAHULUAN}

\section{A. Latar Belakang}

Upaya pemulihan potensi cendana (Santalum album Linn) melalui kegiatan penanaman di Provinsi Nusa Tenggara Timur (NTT) telah dilakukan sejak tahun 1970-an, namun sampai saat ini tingkat keberhasilannya masih rendah rata-rata $20 \%$ (Surata dan Fox, 2000). Rendahnya tingkat keberhasilan penanaman cendana di daerah semiarid disebabkan belum diterapkannya teknologi budidaya secara tepat dan penanaman cendana masih disamakan dengan jenis tanaman lain. Secara khusus tanaman cendana pada awal penanaman di lapangan memerlukan penaung untuk menjaga agar tanaman tidak mengalami stres dan cepat beradaptasi dengan kondisi lingkungannya. Disamping itu tanaman cendana juga memerlukan inang untuk membantu mensuplai sebagian unsur hara dan air dari dalam tanah.

Selama hidupnya tanaman cendana memerlukan tanaman inang mulai dari tingkat persemaian (inang primer) dan lapangan (inang sekunder). Inang ini berfungsi untuk membantu menyerap sebagian unsur hara melalui haustoria. Haustoria berfungsi dengan baik apabila akar tanaman inang telah menempel pada akar cendana (Hamzah, 1976). Menurut Iyenger (1965) dalam Barrett (1989), hanya unsur N, P dan asam amino yang diambil dari tanaman inang, sedangkan unsur $\mathrm{Ca}$ dan $\mathrm{K}$ diambil dari akar cendana. Tanaman inang nyata meningkatkan pertumbuhan tinggi, diameter, bobot kering, dan persen hidup tanaman cendana (Surata, 1993).

Tanaman inang juga dapat berfungsi sebagai pohon penaung, oleh sebab itu disarankan tanaman inang sekunder ditanam lebih awal dari tanaman cendana atau dengan cara menanam jenis tanaman inang yang cepat tumbuh (Surata dan Idris, 2001). Cendana tumbuh lebih baik apabila ditanam di antara cemara (Casuarina junghuniana) atau di dalam hutan dibandingkan dengan tempat terbuka (Hutchins, 1984 dalam Barrett, 1989). Untuk pertimbangan ekonomis tanaman inang dan penaung cendana di lapangan dapat menggunakan semaksemak atau tegakan tanaman yang sudah ada, yang umurnya masih muda dan tajuknya belum menutup terlalu rapat, salah satunya adalah dengan memanfaatkan tegakan Acacia auriculiformis. Beberapa jenis acacia seperti Acacia tracicarpa dan Acacia ampliceps termasuk jenis pohon cepat tumbuh di daerah beriklim kering yang dilaporkan dapat berfungsi dengan baik sebagai tanaman inang sekunder dan juga dapat dipakai sebagai penaung awal tanaman cendana (Radomiljac et al., 1999).

Teknik pemanfaatan tanaman inang sebagai penaung pada pembuatan hutan tanaman cendana adalah salah satu teknik yang dapat diterapankan untuk meningkatkan serapan unsur hara dan juga untuk mengurangi kerusakan bibit cendana akibat sengatan panas cahaya matahari yang ekstrim tinggi dan juga kekeringan di musim kemarau pada awal penanaman di lapangan (Surata dan Idris, 2001). Menurut Hutchine (1984) tanaman cendana yang masih muda menyukai naungan sedangkan inang sekunder yang baru ditanam di lapangan belum berfungsi dengan baik sebagai penaung dan inang. Oleh karena itu untuk sementara di lapangan dapat memanfaatkan semak atau pohon yang sudah ada dengan cara memanipulasi tajuk pohon penaung. Menurut Anthony, Fox, dan Barrett (1993) penaungan tanaman cendana dengan sarlon sampai umur 1 tahun dengan intensitas penyinaran kurang dari $50 \%$ dapat meningkatkan persen tumbuh tanaman dan setelah umur 1 tahun persen tumbuhnya menurun. Raghavan (1948) dalam Barrett (1989) juga menyatakan bahwa tanaman cendana pada awal penanaman sangat peka terhadap kekeringan dan akan segera mati oleh penyinaran matahari langsung yang panjang. Oleh karena itu sampai umur 3-5 tahun diperlukan naungan yang berupa naungan samping dan setelah itu perlu dilakukan pengurangan penaung secara bertahap.

Pemanfaatan Acacia auriculiformis untuk penaung awal dan inang tanaman cendana apabila tajuknya terlalu rapat akan menekan pertumbuhan tanaman pokok karena terjadi persaingan cahaya, air, dan unsur hara. Oleh karena itu tingkat persaingannya perlu dikurangi, salah satunya melalui pemangkasan cabang atau penjarangan pohon penaung atau inang (Surata dan Idris, 2001). Mayhead dan Boothman (1997) melaporkan bahwa penggunaan pohon penaung yang terlalu rapat pada jenis tanaman Quercus petraea menyebabkan pertumbuhan tanaman berkurang. Radomiljac (1994), Surata dan Idris (2001) juga melaporkan bahwa penggunaan Cassia siamea dan Acacia auriculiformis yang terlalu rapat sebagai pohon penaung atau inang akan meningkatkan kematian tanaman cendana. Oleh karena itu intensitas pembukaan tajuk pohon penaung atau inang perlu diatur 
sedemikian rupa sehingga terjadi keseimbangan kebutuhan cahaya, suhu, kelembaban udara, dan ketersedian air tanah yang optimal untuk pertumbuhan tanaman cendana.

\section{B. Tujuan Penelitian}

Berdasarkan permasalahan tersebut di atas maka dilakukan penelitian yang bertujuan untuk mengatahui pengaruh pengurangan penutupan tajuk pohon penaung dan inang Acacia auriculiformis dengan cara pemangkasan cabang terhadap pertumbuhan tanaman cendana.

\section{BAHAN DAN METODE}

\section{A. Tempat dan Waktu Penelitian}

Penelitian dilaksanakan di Oilsonbai, Stasiun Penelitian Balai Penelitian Kehutanan Kupang, pulau Timor, Provinsi NTT, pada bulan Januari 1994 - Januari 2004. Lokasi penelitian berada pada ketinggian $300 \mathrm{~m}$ dari permukaan laut, curah hujan rata-rata 1530 $\mathrm{mm} /$ tahun dengan tipe iklim D (Schmidt dan Ferguson,1951), dan jenis tanah Grumusol yang tersusun dari bahan induk endapan batu kapur (Pusat Penelitian Tanah dan Agroklimat, 1993).

\section{B. Bahan Penelitian}

Dalam penelitian ini digunakan bahanbahan sebagai berikut: biji cendana, inang primer Alternantera sp., polybag ukuran $15 \mathrm{x}$ $20 \mathrm{~cm}$, media semai tanah (top soil) dan pasir. Persemaian konvensional yang digunakan memakai atap plastik gelombang. Pohon penaung atau inang di lapangan menggunakan tegakan Acacia auriculiformis yang telah berumur 5 tahun, jarak tanam $6 \times 6 \mathrm{~m}$, tajuknya belum saling menutup dengan lebar tajuk $2,7 \mathrm{~m}$, tinggi rata-rata $5,2 \mathrm{~m}$ dan diameter $11,2 \mathrm{~cm}$. Untuk mengamati data digunakan alat ukur roll meter, phi band, kaliper, lux meter, termometer udara, dan higrometer.

\section{Metode Penelitian}

\section{Pelaksanaan Teknis Penelitian}

Tahap pertama dari kegiatan penelitian adalah penyiapan bibit cendana di persemaian dengan menggunakan kantung plastik ukuran 15 x $20 \mathrm{~cm}$ yang diisi dengan media tanam berupa campuran tanah (top soil) : pasir dengan perbandingan 4 : 1 . Penyemaian cendana dilakukan dengan penanaman biji secara langsung di polybag yang terlebih dahulu direndam di dalam air biasa selama 24 jam dan ditanam di dalam kantung plastik tiga biji/kantung dengan kedalaman $0,5 \mathrm{~cm}$ yang disertai dengan penanaman inang sekunder Alternantera sp. Inang sekunder ditanam dalam satu polybag yang sama dengan biji cendana yang ditanam dalam bentuk stek pucuk (panjang stek $3 \mathrm{~cm}$ ). Setelah umur satu bulan anakan cendana yang tumbuh disisakan satu pohon. Tajuk tanaman inang yang menaungi anakan cendana dipangkas secara kontinu. Bibit siap ditanam di lapangan pada umur 8 bulan.

Setelah dilakukan seleksi, maka pada awal musim penghujan bibit cendana ditanam diselasela baris tanaman tegakan Acacia auriculiformis dengan jarak tanam $3 \times 3 \mathrm{~m}$. Tegakan A. auriculiformis sebagai penaung bibit cendana telah berumur lima (5) tahun dengan jarak tanam $6 \times 6 \mathrm{~m}$, rata tinggi pohon 5,2 $\mathrm{m}$, diameter $9,43 \mathrm{~cm}$ dan lebar tajuk $2,7 \mathrm{~m}$

\section{Rancangan Penelitian}

Penelitian menggunakan Rancangan Acak Berblok dengan perlakuan intensitas tajuk penaung dengan cara pemangkasan cabang Acacia auriculiformis pada umur 2 tahun setelah tanam cendana. Adapun perlakuan yang dicobakan antara lain intensitas pemangkasan jumlah cabang :

1. $\mathrm{P} 0=$ Kontrol (pemangkasan cabang $0 \%$ )

2. $\mathrm{P} 1=$ Pemangkasan cabang $25 \%$

3. $\mathrm{P} 2=$ Pemangkasan cabang $50 \%$

4. $\mathrm{P} 3=$ Pemangkasan cabang $75 \%$

5. $\mathrm{P} 4=$ Pemangkasan cabang $100 \%$ (pemangkasan cabang yang hanya meninggalkan pucuk pohon saja)

Terubusan cabang pohon penaung atau inang yang tumbuh dipangkas secara kontinu setiap tahun sampai umur 8 tahun. Perlakuan terdiri dari tiga blok, setiap blok terdiri dari 25 tanaman cendana. Untuk mengetahui pengaruh perlakuan maka dilakukan pengamatan tinggi, diameter, dan persen hidup cendana. Disamping pengamatan data pertumbuhan tanaman sebagai data penunjang diamati iklim mikro: suhu udara, intensitas penyinaran matahari, dan kelembaban udara. Pengukurannya dilakukan sebanyak 3 kali yaitu pada saat langit cerah pada jam 12 siang. Pengamatan iklim mikro dilakukan setinggi dada $(1,3 \mathrm{~m})$ di dekat tajuk pohon cendana yang dilakukan pada bulan Agustus pada umur 8 tahun setelah tanam. Data hasil pengamatan diolah secara statistik dengan menggunakan SPSS (Statistical Product and Service Solutions) (Santoso, 2000) yaitu untuk menghitung 
ANOVA, regresi, dan korelasi. Pengaruh perlakuan yang nyata diuji lebih lanjut dengan LSD (Least Significant Diference) yaitu untuk mengetahui perbedaan antara komponen perlakuan.

\section{HASIL DAN PEMBAHASAN}

\section{A. Hasil}

Hasil analisis sidik ragam pertumbuhan tinggi, diameter, dan persen hidup tanaman cendana pada umur 8 tahun setelah tanam disajikan pada Tabel Lampiran 1. Hasil analisis sidik ragam menunjukkan bahwa perlakuan pemangkasan cabang pohon penaung atau inang Acacia auriculiformis nyata meningkatkan pertumbuhan tinggi, diameter, dan persen hidup tanaman cendana.

Selanjutnya berdasarkan hasil uji lanjutan LSD 0,05 menunjukkan bahwa perlakuan pemangkasan cabang pohon penaung atau inang sebesar $25 \%, 50 \%, 75 \%$, dan $100 \%$ nyata meningkatkan pertumbuhan tinggi dan persen hidup, serta perlakuan $50 \%$, $75 \%$, dan $100 \%$ nyata meningkatkan pertumbuhan diameter tanaman cendana.

Tabel(Table) 1. Rata-rata tinggi, diameter, dan persen hidup pertumbuhan tanaman cendana. pada umur 8 tahun (Average of height, diameter, and survival on sandalwood plantations at 8 years old)

\begin{tabular}{|c|c|c|c|c|}
\hline $\begin{array}{c}\text { Nomor } \\
\text { (Number) }\end{array}$ & $\begin{array}{c}\text { Pemangkasan cabang } \\
\text { (Branch pruning) } \\
(\%)\end{array}$ & $\begin{array}{c}\text { Tinggi } \\
\text { (Height) } \\
(\mathrm{cm})\end{array}$ & $\begin{array}{c}\text { Diameter } \\
\text { (Diameter) } \\
(\mathrm{cm})\end{array}$ & $\begin{array}{c}\text { Persen hidup } \\
\text { (Survival) } \\
(\%)\end{array}$ \\
\hline 1 & 0 & $274,223 \mathrm{a}$ & $2,4479 \mathrm{a}$ & $28,67 \mathrm{a}$ \\
\hline 2 & 25 & $317,415 \mathrm{~b}$ & $2,6334 \mathrm{ac}$ & $46,12 \mathrm{~b}$ \\
\hline 3 & 50 & $383,775 \mathrm{bc}$ & $2,9704 \mathrm{bc}$ & $52,23 \mathrm{~b}$ \\
\hline 4 & 75 & $391,390 \mathrm{c}$ & $3,2817 \mathrm{~b}$ & $60,60 \mathrm{~cd}$ \\
\hline 5 & 100 & $346,634 \mathrm{~b}$ & $3,2980 \mathrm{~b}$ & $60,07 \mathrm{~cd}$ \\
\hline
\end{tabular}

Keterangan(Remark): Angka-angka rata-rata yang diikuti oleh huruf yang sama pada kolom yang sama tidak berbeda nyata menurut LSD 0,05 (Mean value with the same letter and same column do not different significantly on $L S D 0,05)$

Selanjutnya untuk menentukan perlakuan pemangkasan cabang yang terbaik yang dapat meningkatkan pertumbuhan tinggi, diameter, dan persen hidup tanaman cendana dilakukan uji analisis regresi dan korelasi. Hasil analisis regresi dan korelasi menunjukkan bahwa persamaan regresi tinggi $Y=265,4079+3,5568 X-0,0268$ $\mathrm{X}^{2}$, dengan nilai korelasi yang sangat kuat $\left(\mathrm{R}^{2}=0,9631\right)$ dan tinggi maksimum $383,42 \mathrm{~cm}$ yang dicapai pada perlakuan pemangkasan cabang 66,35 \%. Persamaan regresi diameter adalah $\mathrm{Y}=2,940+0,006764 \mathrm{X}-0,000037 \mathrm{X}^{2}$ dengan nilai korelasi sangat kuat $\left(\mathrm{R}^{2}=0,9922\right)$ dan diameter maksimum sebesar $3,28 \mathrm{~cm}$ yang dicapai pada perlakuan pemangkasan cabang 100 $\%$. Sedangkan persamaan regresi persen hidup $\mathrm{Y}$ $=29,4020+0,6764 X-0,0037 X^{2}$ nilai korelasi sangat kuat $\left(\mathrm{R}^{2}=0,9938\right)$, dengan persen hidup maksimum cendana $60 \%$ yang dicapai pada perlakuan pemangksan cabang pohon penaung $91 \%$.

Berdasarkan hasil ini maka dapat disimpulkan bahwa, pemangkasan cabang pohon penaung atau inang meningkatkan tinggi, diameter, dan persen hidup maksimum tanaman cendana pada umur 8 tahun masing-masing sebesar $45 \%$, $48 \%$, dan $107 \%$ dibandingkan tanpa pemangkasan cabang (kontrol).

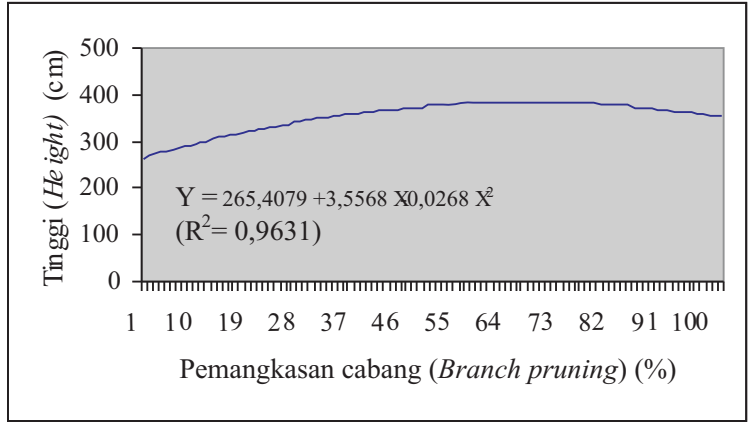

Gambar(Figure) 1. Pengaruh pemangkasan cabang terhadap persen hidup tanaman cendana pada umur 8 tahun (Effects of branch pruning on sandalwood plantation survival at 8 years old) 


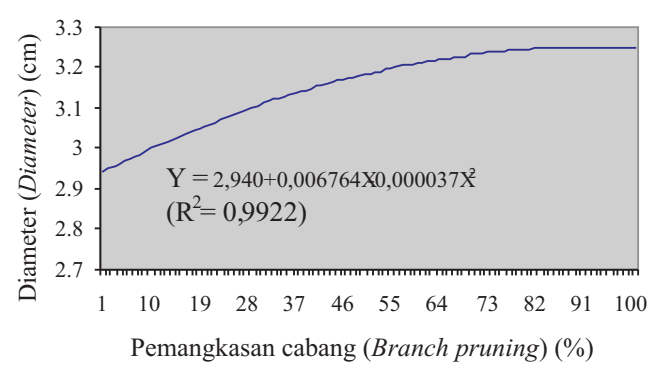

Gambar(Figure) 2. Pengaruh pemangkasan cabang terhadap tinggi tanaman cendana pada umur 8 tahun (Effects of branch pruning on sandalwood plantation height at 8 years old)

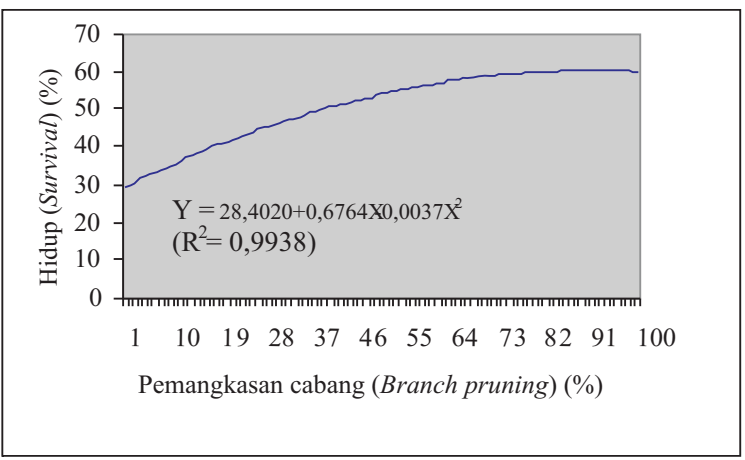

Gambar(Figure) 3. Pengaruh pemangkasan cabang terhadap persen hidup tanaman cendana pada umur 8 tahun (Effects of branch pruning on sandalwood plantation diameter at 8 years old)

Hubungan antara persen hidup, tinggi dan diameter tanaman cendana dengan perlakuan pemangkasan cabang pohon penaung atau inang disajikan pada Gambar 1, 2, dan 3. Pada gambar tersebut terlihat bahwa pertumbuhan tinggi, diameter dan persen hidup tanaman cendana meningkat pada perlakuan intensitas pemangkasan cabang yang semakin besar sampai tingkat maksimum, dan setelah itu akan menurun pada perlakuan pemangkasan cabang yang semakin tinggi.

Hasil rata-rata persen hidup tanaman cendana pada umur 1-8 tahun disajikan pada Tabel 2. Hasil penelitian menunjukkan bahwa pada umur 1-2 tahun sebelum dilakukan perlakuan pemangkasan cabang pohon penaung atau inang, persen hidup tanaman sampai umur 2 tahun masih cukup baik yaitu berkisar 75,33 \%. Hasil analisis Uji LSD 0,05 pada umur 3-5 tahun setelah dilakukan pemangkasan cabang menunjukkan bahwa perlakuan pemangkasan cabang $50 \%$ menghasilkan persen hidup nyata lebih baik, dengan kisaran persen hidup pada umur 5 tahun 52,49-62,21\%, serta pada umur 6-8 tahun pemangkasan cabang $75 \%$ menghasilkan persen hidup nyata lebih baik dengan kisaran persen hidup pada umur 8 tahun 46,12- 60,60\%. Berdasarkan hasil perlakuan intensitas pemangkasan cabang ini dapat disimpulkan bahwa peningkatan pertumbuhan tanaman cendana nyata lebih baik apabila dilakukan pemangkasan cabang $50 \%$ pada umur 35 , dan pemangkasan cabang $75 \%$ pada umur 6 - 8 tahun. Untuk mengetahui intensitas pemangkasan cabang yang dapat menghasilkan persen hidup maksimum pada berbagai tingkat umur tersebut di atas maka dilakukan uji regresi dan korelasi.

Tabel(Table) 2. Rata-rata persen hidup tanaman cendana pada umur 1 - 8 tahun setelah tanam (Mean survival growth on sandalwood plantation at 1 - 8 years old after planting)

\begin{tabular}{|c|c|c|c|c|c|c|c|c|}
\hline \multirow{2}{*}{$\begin{array}{c}\text { Perlakuan } \\
\text { (Treatment) }\end{array}$} & \multicolumn{9}{|c|}{$\begin{array}{c}\text { Persen hidup ( Survival) (\%) } \\
\text { (year) }\end{array}$} & $\begin{array}{c}2 \text { tahun } \\
(\text { year })\end{array}$ & $\begin{array}{c}3 \text { tahun } \\
\text { (year) }\end{array}$ & $\begin{array}{c}4 \text { tahun } \\
\text { (year) }\end{array}$ & $\begin{array}{c}5 \text { tahun } \\
\text { (year) }\end{array}$ & $\begin{array}{c}6 \text { tahun } \\
\text { (year) }\end{array}$ & $\begin{array}{c}7 \text { tahun } \\
(\text { year })\end{array}$ & $\begin{array}{c}8 \text { tahun } \\
\text { (year) }\end{array}$ \\
\hline 0 & $82,45 \mathrm{a}$ & $75,33 \mathrm{a}$ & $49,76 \mathrm{a}$ & $48,33 \mathrm{a}$ & $37,22 \mathrm{a}$ & $31,29 \mathrm{a}$ & $30,66 \mathrm{a}$ & $28,67 \mathrm{a}$ \\
\hline 25 & $79,12 \mathrm{a}$ & $78,31 \mathrm{a}$ & $70,75 \mathrm{~b}$ & $57,98 \mathrm{a}$ & $52,49 \mathrm{~b}$ & $50,33 \mathrm{~b}$ & $49,67 \mathrm{~b}$ & $46,12 \mathrm{~b}$ \\
\hline 50 & $78,93 \mathrm{a}$ & $73,86 \mathrm{a}$ & $70,24 \mathrm{~b}$ & $76,78 \mathrm{~b}$ & $59,60 \mathrm{bd}$ & $53,92 \mathrm{~b}$ & $54,66 \mathrm{~b}$ & $52,23 \mathrm{~b}$ \\
\hline 75 & $85,66 \mathrm{a}$ & $79,12 \mathrm{a}$ & $76,82 \mathrm{~b}$ & $72,31 \mathrm{~b}$ & $66,67 \mathrm{~cd}$ & $63,47 \mathrm{~cd}$ & $62,79 \mathrm{~cd}$ & $60,60 \mathrm{~cd}$ \\
\hline 100 & $84,12 \mathrm{a}$ & $77,23 \mathrm{a}$ & $75,85 \mathrm{~b}$ & $71,67 \mathrm{~b}$ & $62,21 \mathrm{~cd}$ & $61,93 \mathrm{~cd}$ & $61,14 \mathrm{~cd}$ & $60.07 \mathrm{~cd}$ \\
\hline $\begin{array}{c}\text { Rata-rata } \\
\text { (Mean) }\end{array}$ & 82,06 & 76,77 & 68,68 & 65,41 & 55,64 & 52,21 & 51,78 & 49,54 \\
\hline
\end{tabular}

Keterangan (Remark): Angka-angka rata-rata yang diikuti oleh huruf yang sama pada kolom yang sama tidak berbeda nyata pada LSD 0,05 (Mean value with the same letter and same column do not different significantly on LSD 0,05)

Hasil analisis uji regresi dan korelasi hubungan antara persen hidup dan perlakuan pemangkasan cabang pada berbagai umur disajikan pada Tabel 3. Berdasarkan hasil analisis regresi dan korelasi menunjukkan bahwa : pada umur 3 tahun persamaan regresi yang dihasilkan 
$Y=43,544+0,9242 X-0,0062 X^{2}$, nilai korelasi $\left(\mathrm{R}^{2}=0,9552\right)$ dan persen hidup maksimum cendana $78 \%$ yang dicapai pada perlakuan pemangkasan cabang $76 \%$, dan pada umur 6 tahun persamaan regresi yang dihasilkan $\mathrm{Y}=37,1631+$ $0,7080 X-0,0045 X^{2}$ nilai korelasi $\left(R^{2}=0,9737\right)$ dengan persen hidup maksimum $65 \%$ pada perlakuan pemangksan cabang pohon penaung 79 $\%$, serta pada umur 8 tahun persamaan regresi yang dihasilkan $\mathrm{Y}=29,4020+0,6764 \mathrm{X}-0,0037 \mathrm{X}^{2}$. nilai korelasi $\left(\mathrm{R}^{2}=0,9938\right)$, dengan persen hidup maksimum $60 \%$ pada perlakuan pemangkasan cabang $91 \%$ Berdasarkan hasil analisis ini maka dapat disimpulkan bahwa untuk mendapatkan persen hidup maksimum tanaman cendana pemangkasan cabang pohon penaung perlu dilakukan pada umur 3 tahun sebesar $76 \%$, umur 6 tahun sebesar $79 \%$ dan umur 8 tahun sebesar 91
$\%$. Karena pada umur 3 tahun dan 6 tahun selesih nilai persen hidupnya kecil, maka pemangkasan cabang cukup mulai umur 3 dan 8 tahun.

Hasil analisis uji LSD 0,05 intensitas sinar matahari, suhu udara dan kelembaban udara yang disajikan pada Tabel 4 menunjukkan bahwa perlakuan pemangkasan cabang tajuk pohon penaung atau inang Acacia auriculiformis nyata meningkatkan intensitas sinar matahari dan suhu udara serta tidak nyata meningkatkan kelembaban udara. Pemangkasan cabang meningkatkan intensitas sinar matahari $53 \%$ dan suhu udara $14 \%$ yang masuk ke lantai hutan atau tajuk pohon cendana. Kondisi iklim mikro dengan dengan nilai intensitas cahaya 2900 lux, suhu udara $30,8^{\circ} \mathrm{C}$ dan kelembaban udara $80,9 \%$, kondisi ini cukup baik untuk mendukung pertumbuhan cendana.

Tabel(Table) 3. Persamaan regresi, korelasi, dan nilai maksimum persen hidup tanaman cendana pada umur 3, 6, dan 8 tahun (Equation of regression, correlation, maximum value of survival sandalwood plantation at 3,6 , and 8 years old )

\begin{tabular}{|c|l|c|c|c|}
\hline $\begin{array}{c}\text { Umur/Age } \\
\text { Tahun/Year }\end{array}$ & \multicolumn{1}{|c|}{$\begin{array}{c}\text { Regresi } \\
\text { (Regresion) }\end{array}$} & $\begin{array}{c}\text { Korelasi } \\
\text { (Correlation) } \\
\mathrm{R}^{2}\end{array}$ & $\begin{array}{c}\text { Persen hidup } \\
\text { (Survival) } \\
\left(\mathrm{Y}_{\max }\right) \\
(\%)\end{array}$ & $\begin{array}{c}\text { Penaung (Shading) } \\
(\%)\end{array}$ \\
\hline 3 & $\begin{array}{l}\mathrm{Y}=43,544+0,9242 \mathrm{X}-0,0062 \\
\mathrm{X}^{2}\end{array}$ & 0,9552 & 78 & 76 \\
\hline 6 & $\begin{array}{l}\mathrm{Y}=37,1631+0,7080 \mathrm{X}-0,0045 \\
\mathrm{X}^{2}\end{array}$ & 0,9737 & 65 & 79 \\
\hline 8 & $\begin{array}{l}\mathrm{Y}=29,4020+0,6764 \mathrm{X}-0,0037 \\
\mathrm{X}^{2}\end{array}$ & 0,9938 & 60 & 91 \\
\hline
\end{tabular}

Tabel(Table) 4. Rata-rata suhu udara, intensitas cahaya, dan kelembaban udara pada perlakuan pemangkasan cabang pada umur 8 tahun setelah tanam (Average of air temperature, light intensity and air humidity on branch pruning at 8 years old)

\begin{tabular}{|c|c|c|c|c|}
\hline $\begin{array}{c}\text { Nomor } \\
(\text { Number })\end{array}$ & $\begin{array}{c}\text { Perlakuan } \\
\text { (Treatment) }\end{array}$ & $\begin{array}{c}\text { Suhu udara } \\
\text { (Air temperature }) \\
\left({ }^{\circ} \mathrm{C}\right)\end{array}$ & $\begin{array}{c}\text { Intensitas cahaya } \\
\text { (Light intensity) } \\
(\text { Lux })\end{array}$ & $\begin{array}{c}\text { Kelembaban udara } \\
\text { (Air humidity) } \\
(\%)\end{array}$ \\
\hline 1 & 0 & $27,1 \mathrm{a}$ & $1900 \mathrm{a}$ & $83,7 \mathrm{a}$ \\
\hline 2 & 25 & $29,1 \mathrm{a}$ & $2100 \mathrm{a}$ & $82,3 \mathrm{a}$ \\
\hline 3 & 50 & $27,3 \mathrm{a}$ & $2600 \mathrm{~b}$ & $78,6 \mathrm{a}$ \\
\hline 4 & 75 & $30,8 \mathrm{~b}$ & $2800 \mathrm{~b}$ & $80,9 \mathrm{a}$ \\
\hline 5 & 100 & $30,1 \mathrm{~b}$ & $2900 \mathrm{~b}$ & $72,1 \mathrm{a}$ \\
\hline
\end{tabular}

Keterangan(Remarks): Angka-angka rata-rata yang diikuti oleh huruf yang sama pada kolom yang sama tidak berbeda nyata pada LSD 0,05 (Mean value with the same letter and same column do not different significantly on LSD $0,05)$

Analisis regresi dan korelasi dilakukan untuk mengetahui apakah persen hidup tanaman cendana dipengaruhi oleh intensitas cahaya matahari. Berdasarkan hasil analisis regresi dan korelasi liner sederhana menunjukkan bahwa persen hidup cendana nyata dipengaruhi oleh intensitas cahaya matahari $($ sig. $<0,017)$, dengan persamaan $\mathrm{Y}=897,663+31,538 \mathrm{X}$ dan nilai korelasi $\left(\mathrm{R}^{2}=0,941\right)($ Gambar 4$)$. 


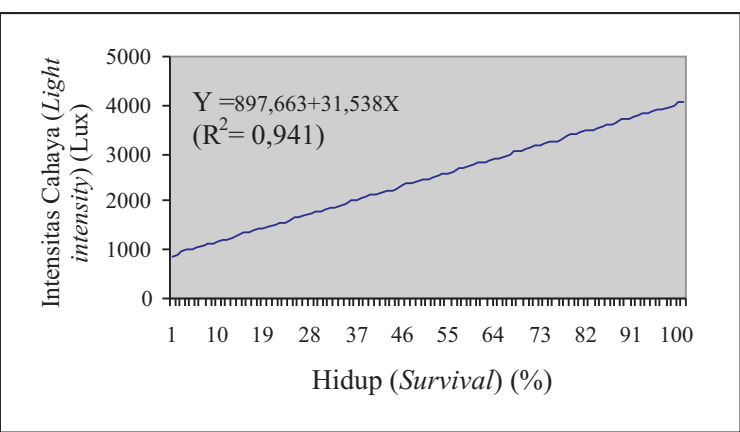

Gambar(Figure) 4. Pengaruh intensitas cahaya terhadap rata-rata persen hidup tanaman cendana umur 8 tahun (Effects of light intensity on sandalwood plantation survival at 8 years old)

Hasil ini juga menunjukkan bahwa persen hidup tanaman cendana meningkat dengan semakin meningkatnya intensitas cahaya. Sedangkan hubungan antara persen hidup dengan suhu tidak nyata berkorelasi (sig. < 0,132), dengan persamaan $\mathrm{Y}=2,109+0.00963 \mathrm{X}$ $\left(\mathrm{R}^{2}=0,785\right)$, serta hubungan antara persen hidup dengan kelembaban udara tidak nyata berkorelasi (sig. $<0,208)$ dengan persamaan $\mathrm{Y}=$ 91,196 - $236 \times\left(R^{2}=0,678\right)$. Hal ini menunjukkan bahwa persen hidup tanaman cendana tidak meningkat dengan semakin naiknya suhu udara dan kelembaban udara.

\section{B. Pembahasan}

Pemanfaatan tegakan Acacia auriculiformis sebagai pohon penaung awal dan inang tanaman cendana yang tidak dilakukan pemangkasan cabang sampai umur 2 tahun menghasilkan persen hidup rata rata 75,33\% (Tabel 2). Persen hidup yang dihasilkan ini nilainya lebih tinggi apabila dibandingkan dengan hasil penelitian penanaman cendana di tempat terbuka $(<20 \%)$ (Surata dan Idris, 2001), dan juga hasil penelitian pada tanaman cendana dengan menggunakan penaung dan inang tumpang sari kacang tanah (Arachis hypogea), kacang hijau (Phaseolus radiatus) dan kacang turis (Cajanus cajan) rata-rata persen hidupnya $50 \%$ (Surata et al., 1995). Persen hidup yang lebih besar pada penggunaan pohon penaung disebabkan karena tanaman cendana pada umur muda memerlukan pohon penaung. Pohon penaung berfungsi untuk membantu mengurangi stress bibit dan juga mempercepat serta meningkatkan adaptabilitas awal bibit terhadap kondisi lingkungan kering di lapangan, sehingga pertumbuhannya meningkat. Menurut Sinha
(1961) cendana akan mati karena kekeringan yang panjang dan berlangsung secara terus menerus dan perlu penaung pada umur pohon yang masih muda. Selain sebagai pohon penaung, tegakan Acacia auriculiformis juga berfungsi sebagai inang sekunder. Inang sekunder pada awal penanaman cendana sangat diperlukan mengingat inang sekunder yang baru ditanam di lapangan belum berfungsi dengan baik sehingga tanaman cendana untuk jangka pendek untuk sementara dapat memanfaatakan inang yang sudah ada (Acacia auriculiformis) untuk membantu menyerap unsur hara dan air dari dalam tanah melalui haustoria, sehingga pertumbuhannya meningkat.

Pemanfaatan tegakan Acacia auriculiformis sebagai pohon penaung dan inang cendana pada umur lebih dari 2 tahun nyata meningkatkan tinggi, diameter, dan persen hidup tanaman cendana (Tabel 1). Pohon penaung atau inang yang terlalu rapat akan menjadi pesaing yang kuat terhadap kebutuhan cahaya, unsur hara, dan air dengan tanaman cendana. Menurut Raghavan (1948) dalam Barrett (1985) pada daerah-daerah yang kekurangan sinar matahari (penaungan terlalu padat) pada umur di atas 3-5 tahun tanaman cendana akan banyak mati. Hal ini karena cendana pada umur tertentu membutuhkan sinar matahari yang lebih besar. Menurut Dupraz (1999) dampak negatif dari penggunaan penaung atas yang terlalu rapat pada jenis pohon juglan sangat nyata menurunkan persen hidup dan diameter,sementara tinggi tanaman masih menguntungkan. Dengan demikian dapat disimpulkan pohon penaung hanya dibutuhkan pada awal penanaman atau pada pohon muda cendana sampai umur 2 tahun dan setelah itu perlu pembukaan tajuk pohon penaung atau inang.

Pertumbuhan tinggi, diameter, dan persen hidup tanaman cendana dipengaruhi oleh kerapatan tajuk pohon penaung atau inang dan pertumbuhan cendana meningkat sampai titik optimum pada perlakuan intensitas pemangkasan cabang yang semakin meningkat dan setelah itu menurun pada pemangkasan cabang yang melebihi titik maksimum (Gambar 1, 2 dan 3). Setelah mencapai titik maksimum pertumbuhan tanaman menurun. Hal ini disebabkan pada umur tersebut sudah terjadi persaingan unsur hara, air, dan cahaya matahari antara pohon cendana dan pohon penaung atau inang yang sangat kuat dengan memanfaatkan tegakan yang tajuknya rapat. Menurut Baker (1950) pertumbuhan tanaman yang mempunyai tinggi dan tajuk 
dominan pada tegakan yang rapat akan menekan pertumbuhan pohon di bawahnya (understory) sehingga akan menyebaban tanaman di bawahnya pertumbuhannya rendah atau mati. Semakin terbuka tajuk pohon penaung atau inang maka akan memberi kesempatan untuk pertumbuhan: tinggi, diameter, dan persen hidup tanaman di bawahnya semakin meningkat. Pertumbuhan tanaman juga sangat dipengaruhi oleh tingkat toleransi tanaman terhadap penyinaran matahari oleh karena itu penggolongan tanaman bisa dibagi menjadi toleran, semitoleran dan intoleran. Jenis cendana termasuk jenis tanaman semitoleran (Faridah, 2007). Menurut Baker (1950) tajuk tanaman yang rapat akan meningkatkan pemangkasan cabang secara alami karena pengaruh persaingan pertumbuhan pohon yang lebih cepat tumbuh ke atas untuk mendapatkan cahaya matahari. Oleh karena itu untuk mengurangi persaingan tanaman di dalam mendapatkan cahaya, air, dan unsur hara pada tegakan hutan tanaman yang terlalu rapat perlu dilakukan penjarangan atau pemangkasan cabang terhadap jenis pohon tajuk di atasnya, sehingga pohon di bawahnya dapat berkembang dengan baik.

Pemangkasan cabang pohon penaung atau inang Acacia auriculiformis pada umur 2 tahun setelah tanam nyata meningkatkan tinggi, diameter dan persen hidup tanaman cendana masing-masing $45 \%$, 48\%, dan $31 \%$ (Tabel 1). Pemangkasan cabang pohon penaung atau inang dapat meningkatkan intensitas sinar matahari sebesar $53 \%$ dan suhu $14 \%$ yang dapat mendukung pertumbuhan tanaman. (Tabel 4). Bergerz dan Dupraz (2000) mengatakan bahwa sistem penaungan dengan pohon penaung samping berupa semak pada tanaman Prunus avium dapat menurunkan radiasi matahari $60 \%$ dan temperatur udara $15 \%$.

Pemangkasan cabang perlu diatur sedemikian rupa agar tidak menimbulkan efek samping terutama perubahan mikroklimat yang mendadak seperti kekeringan yang tinggi sehingga tidak merusak jaringan daun tanaman. Untuk menghindari perubahan mendadak mikroklimat maka pemangkasan cabang pohon penaung atau inang Acacia auriculiformis perlu dilakukan pada umur 3 tahun sebesar $76 \%$ dan pada umur 8 tahun sebesar $91 \%$ (Tabel 2). Pemangkasan cabang pohon penaung yang terlalu tinggi dalam waktu mendadak dapat meningkatkan defisit air dan kematian tanaman. Menurut Salisbury et al. (1992), pada kondisi defisit air di musim kering, dan pada penyinaran yang tinggi akan meningkatkan transpirasi sehingga tanaman mengalami kekurangan air. Pada kondisi yang kering (defisit air) daun bisa mengatur lalu lintas air lewat penutupan stomata, akan tetapi pada kondisi penyinaran yang ekstrim tinggi akan menyebabkan kerusakan atau kematian jaringan daun tanaman yang menyebabkan kematian tanaman (Faridah, 2007).

Persentase hidup tanaman cendana nyata berkorelasi positip.secara linier dengan intensitas cahaya matahari (Tabel 4). Sebagai dampak penaungan terjadi penurunan mikroklimat dan juga energi yang dihasilkan dari proses fotosintesis, transpirasi dan asimilasi menurun sehingga menurunkan metabolisme tanaman (Gardener et al., 1985). Cahaya matahari memegang peranan yang sangat penting dan dibutuhkan oleh cendana untuk meningkatkan persen hidup tanaman terutama untuk kegiatan fotosintesis yang menghasilkan zat makanan untuk menopang energi pertumbuhan tanaman.

Peningkatan cahaya matahari meningkatkan suhu tanaman (Tabel 3). Perubahan suhu akan mempengaruhi perkembangan tanaman. Tanaman memerlukan suhu optimum dalam pertumbuhannya. Menurut Salisbury et al. (1992) kenaikan suhu pada tanaman dari optimum ke maksimum, maka berbagai aktivitas enzim akan menurun satu persatu sehingga mengurangi perkembangan tanaman. Suhu yang tinggi akan menyebabkan reaksi kimia abnormal dan disusul kematian selsel tanaman. Tanaman pada tempat terbuka (tanpa penaung) pada musim kering akan mempunyai suhu tinggi yang akan meningkatkan evapotranspirasi, sehingga absorpsi air tidak bisa mengimbangi transpirasi daun dan akhirnya mengakibatkan kerusakan sel daun. Jika kekurangan air yang tidak diimbangi dari dalam tanah maka protoplasma akan mengering, daun akan layu, sel-sel akan mati. Kekurangan air terjadi pertama pada sel-sel yang terletak di ujung atau pinggir daun (Faridah, 2007)

\section{KESIMPULAN DAN SARAN}

\section{A. Kesimpulan}

1. Pemanfaatan tegakan Acacia auriculiformis sebagai pohon penaung dan inang cendana sampai umur 2 tahun yang tidak dilakukan pemangkasan cabang menghasilkan persen hidup cendana yang cukup baik yaitu ratarata $75 \%$. 
2. Pemangkasan cabang pohon penaung atau inang Acacia auriculiformis pada umur 2 tahun setelah tanam nyata meningkatkan tinggi, diameter, dan persen hidup tanaman cendana masing-masing $45 \%, 48 \%$, dan $31 \%$.

3. Persen hidup tanaman cendana paling baik dihasilkan pada perlakuan pemangkasan cabang pohon penaung atau inang Acacia auriculiformis sebesar $76 \%$ pada umur 3 tahun dan $91 \%$ pada umur 8 tahun.

4. Pemangkasan cabang pohon penaung atau inang dapat meningkatkan suhu udara $14 \%$ dan radiasi penyinaran matahari $53 \%$.

5. Persen hidup tanaman cendana nyata berkorelasi positif secara linier dengan intensitas cahaya matahari.

\section{B. Saran}

1. Untuk meningkatkan pertumbuhan tanaman cendana di lapangan maka perlu menggunakan penaung awal dan inang sekunder, salah satunya dapat memanfaatankan tegakan semak atau pohon yang sudah ada di lokasi penanaman.

2. Penggunaan tegakan pohon sebagai penaung atau inang perlu dipilih jenis pohon dan kerapatan tajuk yang sesuai.

3. Untuk mengatasi pohon penaung atau inang yang tajuknya rapat agar tidak menimbulkan persaingan maka perlu dilakukan pemangkasan cabang atau penjarangan sampai mencapai kondisi kerapatan tajuk yang optimal.

\section{DAFTAR PUSTAKA}

Anthony, T., J. E. D. Fox. and D. R. Barrett. 1993. Environmental Effects of Early Growth of Santalum album L. with Particular Reference to Shade Regimes. Santalum 13:29-47.

Baker, F. S. 1950. Principles of Silviculture. Mc. Graw Hill Book Company. Inc. New York.

Barret, D. R. 1989. A Brief Note on the Regeneration of Sandal to Suplement Existing Stock in Forest or to Replace Sandal that May Killed by Spike. In. Santalum album (Indian Sandalwood) literature review, Mulga Research Centre. Western Australian Institute of Technology. Perth.
Bergez, J. E. and C. Dupraz, 2000. Effect of Ventilation on Growth of Prunus avium Seedlings Grown in Tree Shelters. Agr and For.Met. 104 : 199-214

Dupraz, C. and J. E. Bergez. 1999. Carbon Dioksida Limitation of the Photosyntesis of Prunus avium L Seedlings Inside an Unventilated Treeshelter. For. Ecol. Mgmt. 119:89-97

Faridah, E. 2007. Fisiologi Stress. Program Studi Ilmu Kehutanan, Sekolah Pasca Sarjana. Universitas Gadjah Mada. Yogyakarta.

Gardener, F.P., R. B. Peace. and R. L. Mitchell. 1985. Physiology of Crop Plants. The Iowa State University Press. USA.

Hamzah, Z. 1976. Sifat Silvika dan Silvikultur Cendana (Santalum album L.) di Pulau Timor. Laporan No.227. Lembaga Penelitian Hutan, Bogor.

Mayhead, G. J. and I. R. Boothman. 1997. The Effect of Treeshelter Height on Early Growth of Sessile Oak (Quercus petraea (matt) Liebl). J. For. 70:151-155.

Pusat Penelitian Tanah dan Agroklimat.1993. Peta Tanah Provinsi Nusa Tenggara Timur. Pusat Penelitian Tanah dan Agroklimat. Badan Penelitian dan Pengembangan Pertanian Bogor.

Radomiljac, A. M., J. A. Mc.Comb. and J. F. Mc.Grath. 1999. Intermediate Host Influences on the Root Hemi-parasite Santalum album L. Biomas Partitioning..For. Ecol. and Mgmt. 143:153.

Schmidt, F. G. and J. M. A. Ferguson. 1951. Rainfall Types Based on Wet and Dry Period Rations for Indonesia with Western New Guinea. Verhand 42. Direktorat Meteorologi dan Geofisika. Djakarta.

Salisbury, B. F. and C. W. Ross. 1992. Plant Physiology. Pergamon Press. $4^{\text {th }}$ edition. Oxford, London, New York, Paris

Santoso, S. 2000. SPSS Statistik Parametrik. PT. Elex Media Komputindo. Kelompok Gramedia. Jakarta.

Surata, I. K. 1993. Pengaruh Jenis Inang terhadap Pertumbuhan Semai Cendana (Santalum album L.). Santalum 9: 1-9. 
Surata, I. K., Harisetijono. dan M. Sinaga. 1995. Pengaruh Penanaman Sistem Tumpangsari terhadap Pertumbuhan Cendana (Santalum album L.). Savana 20 $: 17-25$

Surata, I. K. and J. E. D. Fox. 2000. Government Initiatives to Encourage Land Holders to
Participate in Planting Sandalwood in East Nusa Tenggara. Paper Presented on the IUFRO Working Group Meeting at Cairns, Queensland, Australia, 7-12 January 2000.

Surata, I.K. dan M. Idris. 2001. Status Penelitian Cendana di Provinsi Nusa Tenggara Timur. Berita Biologi 5 (5) :521-539 
Lampiran(Appendix) 1. Analisis keragaman tinggi, diamater dan persen hidup tanaman cendana (Analysis of variance for height, diameter, and survival of cendana plants)

\begin{tabular}{|c|c|c|c|c|c|c|}
\hline $\begin{array}{l}\text { Parameter } \\
\text { (Parameter) }\end{array}$ & $\begin{array}{c}\text { Sumber } \\
\text { Keragaman } \\
\text { (Source of } \\
\text { variance) }\end{array}$ & $\begin{array}{l}\text { Db } \\
(d f)\end{array}$ & $\begin{array}{c}\text { JK } \\
(S S)\end{array}$ & $\begin{array}{l}\mathrm{KT} \\
(M S)\end{array}$ & F & Sig. \\
\hline $\begin{array}{l}\text { Tinggi } \\
\text { (height) }\end{array}$ & $\begin{array}{l}\text { Perlakuan } \\
\text { (Treament) } \\
\text { Blok (Block) } \\
\text { Acak (Error) }\end{array}$ & $\begin{array}{l}4 \\
2 \\
8\end{array}$ & $\begin{array}{l}9092,238 \\
2649,091 \\
3237,774\end{array}$ & $\begin{array}{r}5818,448 \\
1324,546 \\
462,539\end{array}$ & $\begin{array}{r}12,579 \\
2,864\end{array}$ & $\begin{array}{l}0,002^{*} \\
0,123\end{array}$ \\
\hline & Total & 14 & 34252,027 & & & \\
\hline $\begin{array}{l}\text { Diameter } \\
\text { (diameter) }\end{array}$ & $\begin{array}{l}\text { Perlakuan } \\
\text { (Treament) } \\
\text { Blok (Block) } \\
\text { Acak (Error) }\end{array}$ & $\begin{array}{l}4 \\
2 \\
8\end{array}$ & $\begin{array}{l}1,683 \\
0,333 \\
0,443\end{array}$ & $\begin{array}{l}0,421 \\
0,167 \\
0,053\end{array}$ & $\begin{array}{l}7,605 \\
3,013\end{array}$ & $\begin{array}{l}0,008^{*} \\
0,106\end{array}$ \\
\hline & Total & 14 & 2.460 & & & \\
\hline $\begin{array}{l}\text { Hidup } \\
\text { (Survival) }\end{array}$ & $\begin{array}{l}\text { Perlakuan } \\
\text { (Treament) } \\
\text { Blok (Block) } \\
\text { Acak (Error) }\end{array}$ & $\begin{array}{l}4 \\
2 \\
8\end{array}$ & $\begin{array}{r}1618,667 \\
51,773 \\
222,933\end{array}$ & $\begin{array}{r}404,667 \\
25,667 \\
27,867\end{array}$ & $\begin{array}{r}14,522 \\
0,928\end{array}$ & $\begin{array}{l}0,001 \\
0,434\end{array}$ \\
\hline & Total & 14 & 1893.333 & & & \\
\hline
\end{tabular}

Keterangan (remark): *Berbeda nyata pada taraf uji $5 \%$ (Significant of 0,05 level) 